\title{
A Simple Construction of a Bile Acid Based Dendritic Light Harvesting System
}

\section{N. Vijayalakshmi and Uday Maitra*,†}

Department of Organic Chemistry, Indian Institute of Science, Bangalore 560012, India

maitra@orgchem.iisc.ernet.in

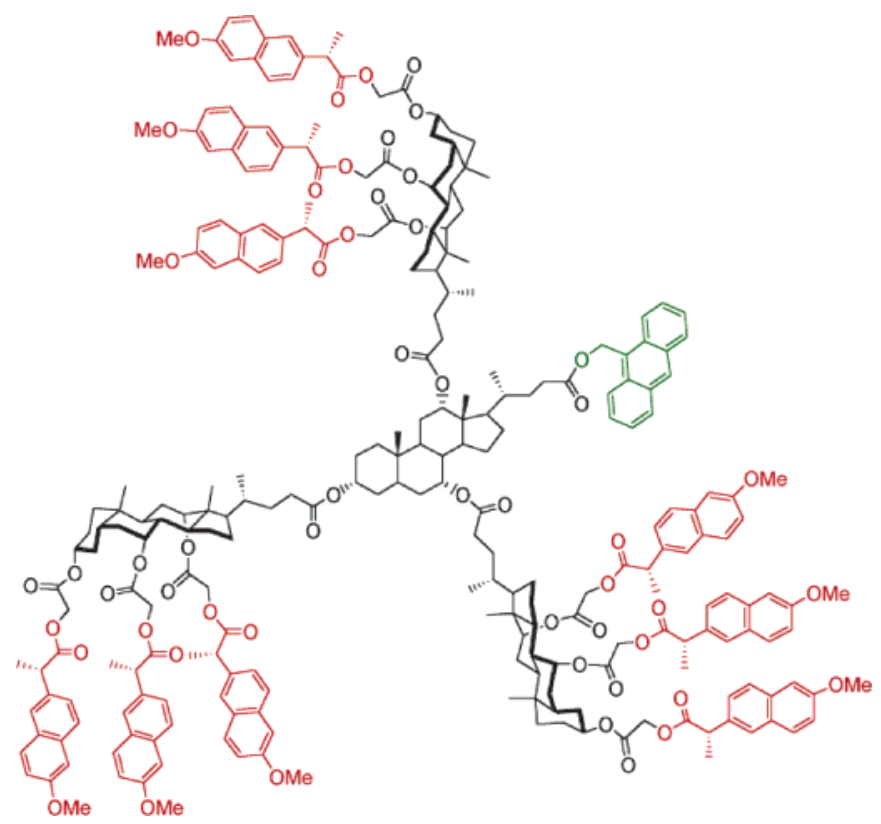

A facile synthesis of a cholic acid derived dendritic structure labeled with nine naproxens and a single anthracene is reported. This multichromophoric, novel dendritic construct acts as an efficient molecular light harvester.

Dendrimers are monodisperse, polymeric materials of nanometric dimensions with precisely defined structures and multiple controllable functionalities. ${ }^{1}$ These features have been utilized for diverse applications including drug or gene delivery, diagnostics, catalysis, and molecular recognition. ${ }^{2}$

\footnotetext{
* To whom correspondence should be addressed. Fax: +91-80-23600529.

$\dagger$ Also at the Chemical Biology Unit, Jawaharlal Nehru Centre for Advanced Scientific Research, Bangalore 560 064, India.

(1) (a) Tomalia, D. A.; Naylor, A. M.; Goddard, W. A., III. Angew. Chem., Int. Ed. Engl. 1990, 29, 138. (b) Newkome, G. R.; Moorefield, C. N.; Vögtle, F. Dendritic Molecules: Concepts, Syntheses, Perspectives; VCH: Weinheim, 1996. (c) Matthews, O. A.; Shipway, A. N.; Stoddart, J. F. Prog. Polym. Sci. 1998, 23, 1. (d) Fréchet, J. M. J.; Tomalia, D. A Dendrimers and Other Dendritic Polymers; John Wiley \& Sons Ltd.: New York, 2001.
}

In recent years there has been specific interest in dendritic molecular light harvesting systems because of their potential optical applications. ${ }^{3,4}$ Several groups have elegantly dem-

(2) (a) Zeng, F.; Zimmerman, S. C. Chem. Rev. 1997, 97, 1681. (b) Liu, M.; Fréchet, J. M. J. Pharm. Sci. Technol. Today 1999, 2, 393. (c) Stiriba, S. E.; Frey, H.; Haag, R. Angew. Chem., Int. Ed. 2002, 41, 1329. (d) Zimmerman, S. C.; Zharov, I.; Wendland, M. S.; Rakow, N. A.; Suslick, K. S. J. Am. Chem. Soc. 2003, 125, 13504.

(3) (a)Vögtle, F.; Gestremann, S.; Kauffmann, C.; Ceroni, P.; Vicinelli, V.; Balzani, V. J. Am. Chem. Soc. 2000, 122, 10398. (b) Serin, J. M.; Brousmiche, D. W.; Fréchet, J. M. J. J. Am. Chem. Soc. 2002, 124, 11848 (c) Hahn, U.; Gorka, M.; Vögtle, F.; Vicinelli, V.; Ceroni, P.; Maestri, M., Balzani, V. Angew. Chem., Int. Ed. 2002, 41, 3595. (d) Jordens, S.; Belder, G. De.; Lor, M.; Schweitzer, G.; Van der Auweraer, M.; Weil, T.; Reuther, E.; Müllen, K.; De Schryver, F. C. Photochem. Photobiol. Sci. 2003, 3, 177. 
onstrated the use of dendrimers as light harvesting antennae with efficient energy transfer properties. ${ }^{4}$

Bile acids are excellent building blocks for dendritic construction $^{5}$ because of their many interesting features. They are readily available, chiral, facial amphiphiles with complementary functionalities. Moreover, because of the large size of the bile acid units, a dendritic structure consisting of only a few such repeat units can have a globular shape with multiple functionalizable groups. In addition, these dendritic scaffolds are potentially biodegradable because of the presence of hydrolyzable ester bonds. These promising characteristics, coupled with the advantages of dendrimer-based drug carriers, ${ }^{6}$ prompted us to design dendrimer 12 with multiple naproxen ${ }^{7}$ units at the periphery. Since naproxen is photoactive with a high fluorescence quantum yield, we could further explore the photophysical properties of this multichromophoric dendrimer. We find that it is possible to localize the energy absorbed by the peripheral chromophores through intramolecular energy transfer by functionalizing the carboxyl group on the side chain with an anthracenyl moiety. Here we report the remarkably simple synthesis and studies on the optical properties of these dendritic systems.

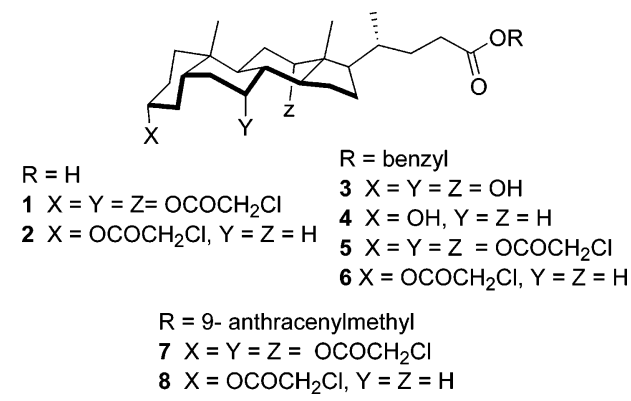

The dendritic structures were prepared from cholic acid as the starting material, using a straightforward synthetic strategy in high yields. Tris(chloroacetylated) cholic acid (1) and benzyl cholate (3) were synthesized using routine procedures. ${ }^{5 \mathrm{~b}}$ Compound $\mathbf{1}$ was converted to its acid chloride and reacted with 3 following the Oppenauer protocol ${ }^{8}$ to generate tetramer 9 with nine easily functionalizable chloroacetate groups $(72 \%)$. To synthesize the tetramer appended

(4) (a) Devadoss, C.; Bharathi, P.; Moore, J. S. J. Am. Chem. Soc. 1996 , 118, 9635. (b) Adronov, A.; Gilat, S. L.; Fréchet, J. M. J.; Ohta, K.; Neuwahl, F. V. R.; Fleming, G. R. J. Am. Chem. Soc. 2000, 122, 1175. (c) Melinger, J. S.; Pan, Y.; Klieman, V. D.; Peng, Z.; Davis, B. L.; McMorrow, D.; Lu, M. J. Am. Chem. Soc, 2002, 124, 12002. (d) Liu, D.; De Feyter, S.; Cotlet, M.; Stefan, A.; Wiesler, U. M.; Hermann, A.; Grebel-Koehler, D.; Qu, J.; Müllen, K.; De Schryver, F. C. Macromolecules 2003, 36, 5918. (e) Thomas, K. R. J.; Thompson, A. L.; Sivakumar, A. V.; Bardeen, C. J.; Thayumanavan, S. J. Am. Chem. Soc. 2005, 127, 373.

(5) (a) Balasubramanian, R.; Rao, P.; Maitra, U. Chem. Commun. 1999 2353. (b) Balasubramanian, R.; Maitra, U. J. Org. Chem. 2001, 66, 3035 (c) Ropponen, J.; Tamminen, J.; Lahtinen, M.; Linnanto, J.; Rissanen, K.; Kolehmainen, E. Eur. J. Org. Chem. 2005, 73

(6) (a) Haba, K.; Popkov, M.; Shamis, M.; Lerner, R. A.; Barbas, C. F., III; Shabat, D. Angew. Chem., Int. Ed. 2005, 44, 716. (b) Ihre, H. R.; De. Jesús, O. L. P.; Szoka, F. C.; Fréchet, J. M. J. Bioconjugate Chem. 2002, 13, 443. (c) Patri, A. K.; Majoros, I. J.; Baker, J. R., Jr. Curr. Opin. Chem. Biol. 2002, 6, 466.

(7) The $S$-enantiomer of naproxen is a non-steroidal anti-inflammatory drug (NSAID) which is used as a therapeutic agent for rheumatoid and osteo-arthritis

(8) Oppenauer, R. V. Monatsh. Chem. 1966, 97, 62.
Scheme 1. Synthesis of Compounds $\mathbf{1 0}$ and $\mathbf{1 1}$

(i) $\mathrm{COCl}_{2}, \mathrm{CH}_{2} \mathrm{Cl}_{2}$

(ii) $3, \mathrm{CaH}_{2}, \mathrm{BnEt}_{3}{ }^{+} \mathrm{Cl}^{-}$

toluene reflux
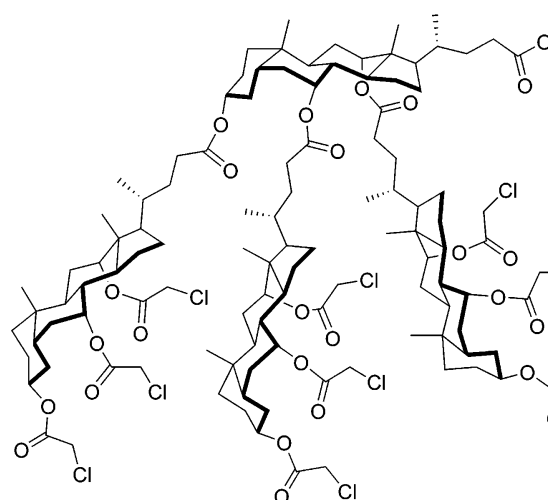

OR

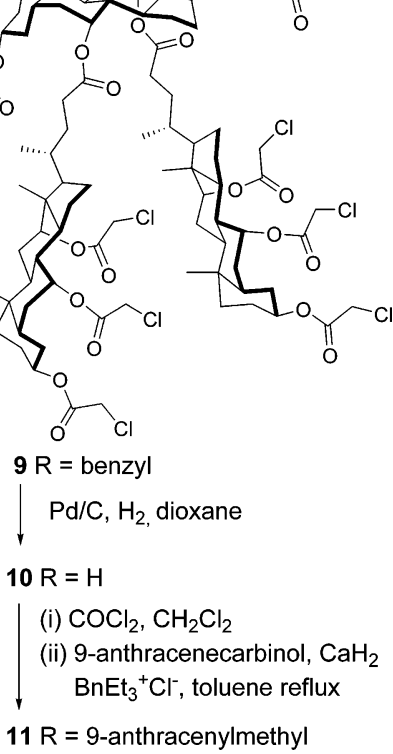

with anthracene (11), compound 9 was hydrogenolyzed $\left(\mathrm{Pd} / \mathrm{C}, \mathrm{H}_{2}\right.$, dioxane) to dendron $10(92 \%)$, which was converted to its acid chloride and then coupled with anthracene-9-carbinol (70\%) (Scheme 1). Dendrons 9 and 11 were then reacted with an excess of the potassium salt of naproxen in DMSO to generate $\mathbf{1 2}$ (84\% yield) and $\mathbf{1 3}(80 \%$ yield), respectively. (Scheme 2).

Hence, by taking advantage of the high reactivity of the chloroacetyl group, we have successfully attached multiple naproxen units at the periphery of per(chloroacetylated) bile acid based dendrons. ${ }^{9}$

In a similar way, four simpler model compounds were synthesized using monomeric bile acid units for comparitive studies with the dendritic system. Compounds $\mathbf{1 4}$ and $\mathbf{1 6}$ were synthesized from $\mathbf{5}$ and $\mathbf{6}$, respectively, by reaction with the potassium salt of naproxen. Compounds 15 and 17 were synthesized from $\mathbf{1}$ and $\mathbf{2}$, respectively, by first converting to their anthracenyl esters ( 7 and $\mathbf{8}$ ) followed by coupling with the naproxen salt.

The dendritic structures were soluble in chloroform, THF, and acetonitrile. All the compounds were characterized by NMR and MALDI-TOF/ESI mass spectrometry, and the purity of all the naproxen derivatives was determined by reverse-phase HPLC, which showed a single peak in each case (see Supporting Information).

The molar extinction coefficients (corresponding to naproxen absorption) of $\mathbf{1 2}$ and $\mathbf{1 4}$ were nearly 9 and 3 times higher,

(9) (a) We have also recognized that this is a potentially efficient way to construct bile acid derived large dendritic structures (unpublished observations from this laboratory). (b) See also: Vinogradov, S. A. Org. Lett. 2005, 7, 1761. 
Scheme 2. Synthesis of Compounds $\mathbf{1 2}$ and $\mathbf{1 3}$

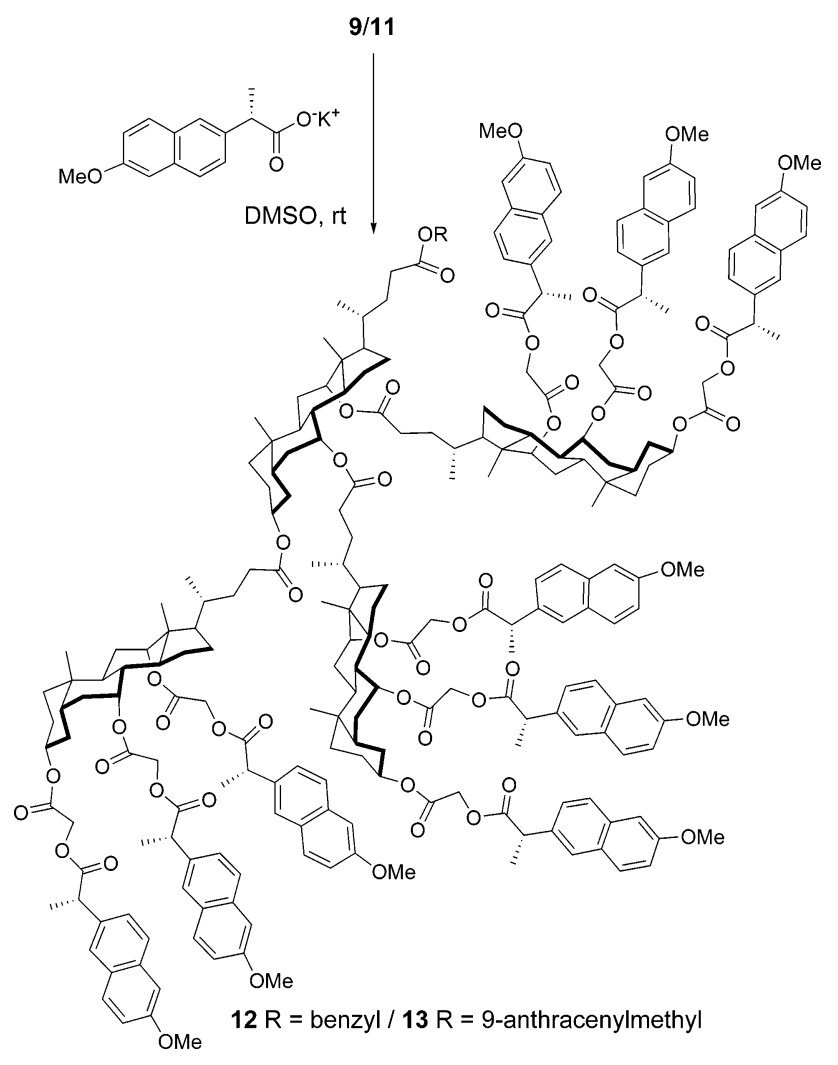

respectively, compared to those of $\mathbf{1 6}$ in $\mathrm{CH}_{3} \mathrm{CN}$. This linear increase of absorption with increasing number of naproxen units suggests the absence of ground-state interactions between the chromophores (Figure 1). The absorption spectrum of $\mathbf{1 7}$ was similar to an equimolar mixture of naproxen and 9-anthracenemethanol (except for a $2 \mathrm{~nm}$ red shift in the anthracenyl absorption). Compound $\mathbf{1 3}$ and $\mathbf{1 5}$ showed similar absorption characteristics with a linear increase in the naproxen absorption, analogous to $\mathbf{1 2}$ and 14, respectively (Figure 2, inset). This indicates the absence of ground-state interactions between the naproxen and anthracenyl moieties. In the $275-290 \mathrm{~nm}$ absorption region the molar extinction coefficient of naproxen is much greater than that of anthracene-9-carbinol (see Supporting Information). Hence, excitation in this region would mainly excite the naphthalene chromophore (see Supporting Information).

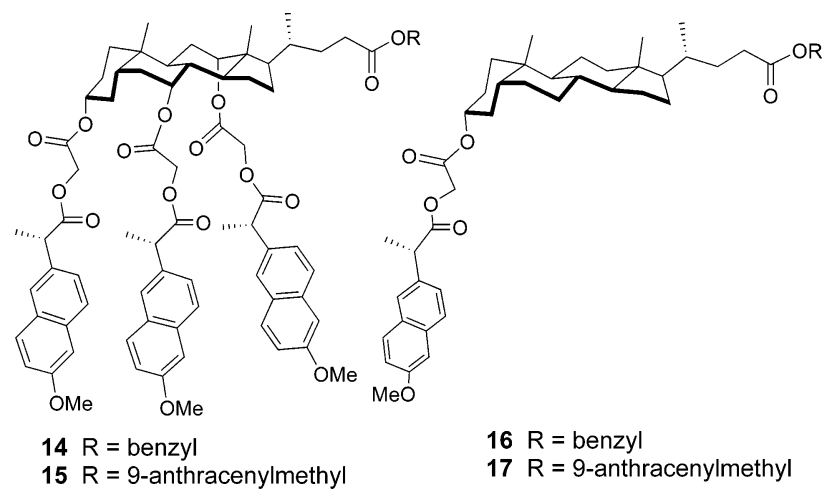

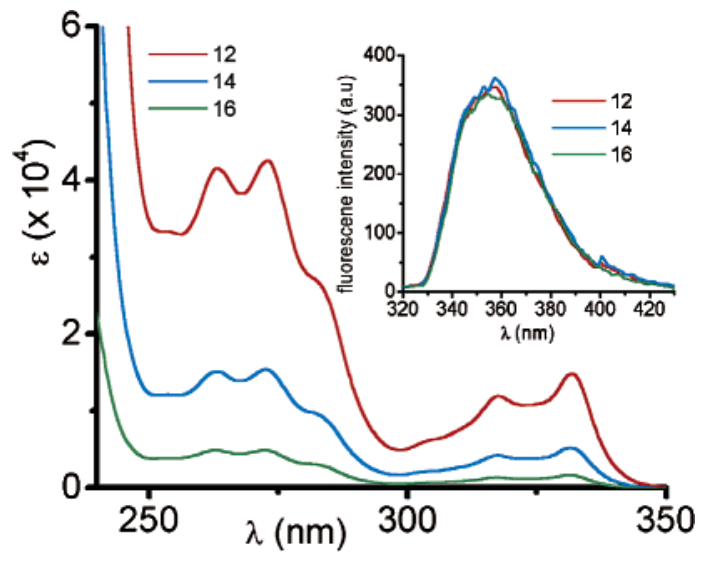

Figure 1. Absorption spectra of 12, 14, and 16 in $\mathrm{CH}_{3} \mathrm{CN}$. The inset shows the emission spectra of $\mathbf{1 2}, \mathbf{1 4}$, and $\mathbf{1 6}$ at $0.22,0.7$, and $2 \mu \mathrm{M}$, respectively, in $\mathrm{CH}_{3} \mathrm{CN}\left(\lambda_{\mathrm{ex}}=275 \mathrm{~nm}\right)$.

The fluorescence study of $\mathbf{1 2}, \mathbf{1 4}$, and $\mathbf{1 6}$ in acetonitrile $\left(\lambda_{\mathrm{ex}}=275 \mathrm{~nm}\right)$ showed a maximum at $353 \mathrm{~nm}$, with a linear increase in fluorescence intensity with the number of naproxens - a desirable feature for amplification of photophysical properties (inset of Figure 1, concentration adjusted scale). No excimer formation was observed in the concentration range of $10^{-6}-10^{-7} \mathrm{M}$ in acetonitrile. The emission spectra of $\mathbf{1 5}$ and $\mathbf{1 7}\left(\lambda_{\mathrm{ex}}=275 \mathrm{~nm}\right)$ exhibited fluorescence characteristics, chiefly that of the anthracene chromophore, with maxima at 390, 412, and $436 \mathrm{~nm}$ and a shoulder at 465 $\mathrm{nm}$ (with weak emission from the naproxen chromophore). Hence, there is energy transfer from naproxen (donor) to the anthracenyl (acceptor) moiety on the side chain.

The emission spectra of mixtures of naproxen and 9-anthracenemethanol (under similar experimental conditions) exhibited fluorescence characteristics, chiefly that of naproxen, which confirms the intramolecular nature of the energy

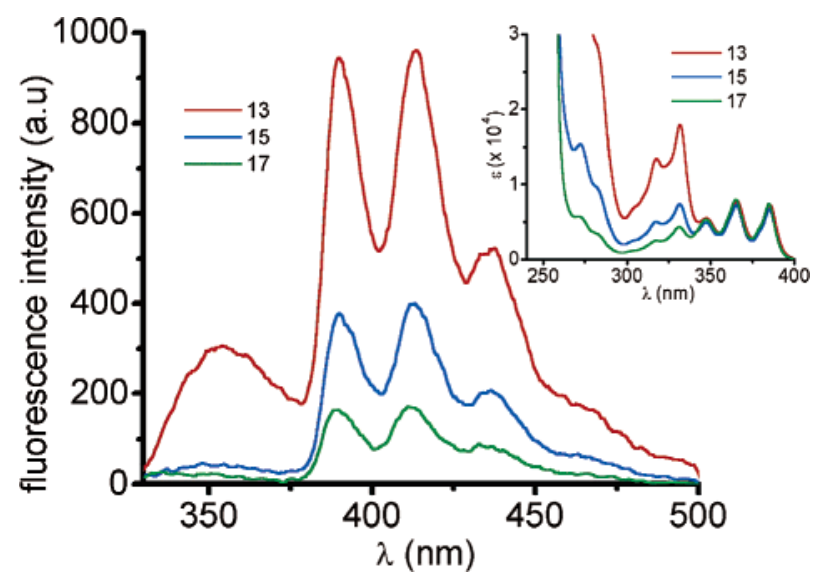

Figure 2. Emission spectra of 13, 15, and 17 at $1 \mu \mathrm{M}$ in $\mathrm{CH}_{3} \mathrm{CN}$ $\left(\lambda_{\mathrm{ex}}=275 \mathrm{~nm}\right)$. The inset shows the absorption spectra of $\mathbf{1 3}, \mathbf{1 5}$, and 17 in $\mathrm{CH}_{3} \mathrm{CN}$. 
transfer in $\mathbf{1 5}$ and 17. Compound $\mathbf{1 5}$ can be considered to be the basic building block of dendrimer 13. Hence, the emission characteristic of $\mathbf{1 3}$ was compared with that of $\mathbf{1 5}$. When tetramer 13 was excited at $275 \mathrm{~nm}$, intense emission from the anthracene moiety was observed, which was much higher than that of 15, but the residual emission from the naproxen was higher compared to $\mathbf{1 5}$ (Figure 2). The estimated efficiencies of energy transfer based on donor quenching ${ }^{5}$ were $80 \%$ for $\mathbf{1 3}$ and $92 \%$ for $\mathbf{1 5}$. Molecular modeling (Figure 3, showing one possible conformation) suggests that in $\mathbf{1 3}$ the probable distance between donor and acceptor is in the range of $13-28 \AA$ (estimated Forster's

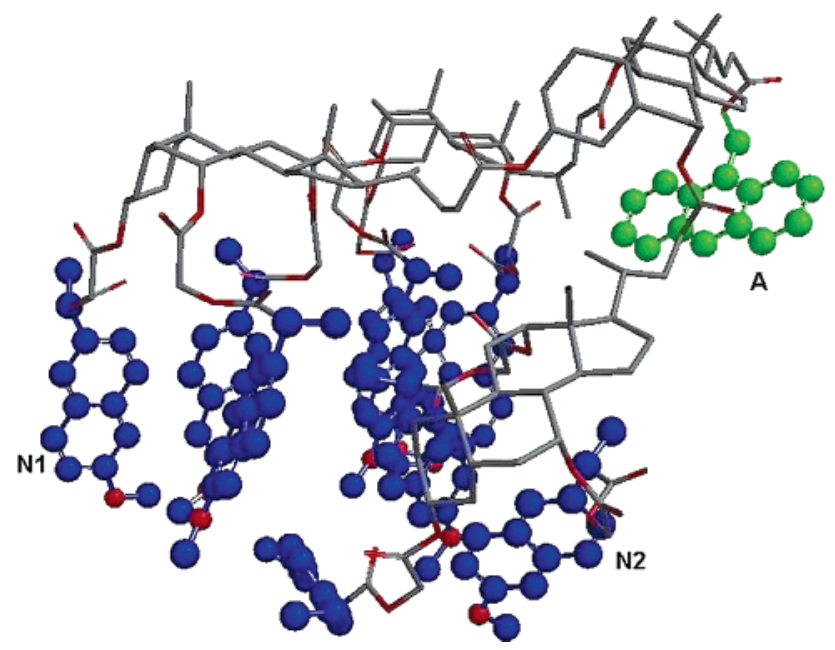

Figure 3. Spartan '04 (molecular mechanics) minimized model of $\mathbf{1 3}$ (one possible conformation). Naproxen (blue) and anthracene (green) N1-A: $23 \AA$; N2-A: $13 \AA$. distance ${ }^{10}$ in $\mathrm{CH}_{3} \mathrm{CN}$ for the donor-acceptor pair is $28 \AA$ ). Hence, the decreased efficiency of the tetramer (compared to 15) may be due to increase in the average distance between some of the donor units and the acceptor.

In conclusion, it is worth noting that by applying a simple synthetic strategy we have been able to construct a novel first generation dendritic light harvesting system with a large number of chromophoric groups with energy transfer efficiencies comparable to those of other reported systems. ${ }^{4}$ We have demonstrated light harvesting in the UV range, but the flexible synthetic scheme allows for facile modification of the periphery and the core with other chromophores. These dendritic structures are also promising candidates for drug delivery applications. In vitro enzymatic cleavage of the naproxen conjugates and detailed photophysical studies are currently under investigation, and these results will be published elsewhere.

Acknowledgment. We thank the Department of Science and Technology, New Delhi, for financial assistance (Grant no. SR/S1/OC-11/2004). N.V. thanks the UGC for a fellowship.

Supporting Information Available: Synthetic procedure and characterization for 13, absorption and emission spectra of naproxen and 9-anthracenemethanol, and HPLC profile for $\mathbf{1 2}$ and 13. This material is available free of charge via the Internet at http://pubs.acs.org.

\section{OL050809M}

(10) Latt, S. A.; Cheung, H. T.; Blout, E. R. J. Am. Chem. Soc. 1965, 87,995 